\section{IQ and mental disorder in young men}

\author{
ERIK LYKKE MORTENSEN, HOLGER JELLING SØRENSEN, \\ HANS HENRIK JENSEN, JUNE MACHOVER REINISCH \\ and SARNOFF A. MEDNICK
}

Longitudinal research shows that many mental disorders do not arise de novo in adult life but have their roots in childhood (Jones et al, 1994; Caspi et al, 1996; Cannon et al, 2001). Most researchers investigating the relationship between cognitive development and risk of mental disorder have concentrated their efforts on schizophrenia. Thus, Swedish and Israeli conscript studies have consistently supported the existence of a robust relationship between low IQ test scores and risk of schizophrenia (David et al, 1997; Davidson et al, 1999; Gunnell et al, 2002). Comparatively few studies have examined possible relationships between IQ and other psychiatric disorders, although associations between low scores on IQ tests and risk of non-schizophrenic psychotic disorders (David et al, 1997) as well as risk of severe depression (Zammit et al, 2004) have also been observed in the Swedish conscript study. Perhaps more remarkably, a recent cross-sectional study has provided evidence that most diagnostic categories are associated with low IQ scores in male adolescents (Weiser et al, 2004). Hence, there is a rationale for conducting longitudinal studies examining whether low IQ test scores are specifically associated with schizophrenia or are a marker of increased vulnerability to the development of a broader range of psychiatric disorders. We conducted a prospective study spanning about 20 years and linking data on IQ in early adulthood with the risk of hospitalisation for a broad range of psychiatric disorders.

\section{METHOD}

\section{The Copenhagen Perinatal Cohort}

The Copenhagen Perinatal Cohort consists of 9125 individuals born during the period October 1959 to December 1961 at the maternity department of the Copenhagen University Hospital, Rigshospitalet. A total of 8400 infants survived the first month after birth. When the cohort was established, demographic, socio-economic, prenatal and postnatal data were recorded prospectively during pregnancy, at delivery and at a 1-year examination (ZachauChristiansen \& Ross, 1975). Parental social status was recorded at the 1-year examination using a combined scale, rated from 1 to 8 , based on breadwinner's occupation, breadwinner's education, type of income (wage/salary) and quality of housing.

\section{The Danish Psychiatric Central Register}

The Danish Psychiatric Central Register has been computerised since 1 April 1969 (Munk-Jørgensen \& Mortensen, 1997). It contains data on all admissions to Danish psychiatric in-patient facilities. Until 1994, diagnoses were coded according to ICD-8 (World Health Organization, 1974). Since 1994 diagnoses have been coded according to ICD-10 (World Health Organization, 1992).

\section{Draft records}

With the exception of individuals with disqualifying diseases (such as epilepsy and diabetes) and individuals who volunteer for military service, all Danish men are required to appear before the draft board when they become liable for conscription at the age of 18 years. Appearing before the draft board primarily involves a medical assessment, but also includes IQ testing. Draft board information including IQ test scores has been collected for all male members of the cohort by the Prenatal Development Project, a large-scale study of the effects of prenatal and perinatal factors on human development (Reinisch et al, 1993).

The IQ test used by the Danish military draft board is the Børge Priens Prøve (BPP). It is a 45 min group test with four sub-tests (letter matrices, verbal analogies, number series and geometric figures) and a total score ranging from 0 to 78 . The total score correlates 0.82 with the Full Scale IQ of Wechsler's Adult Intelligence Scale (WAIS; Wechsler, 1958), indicating that the BPP is a high-quality measure of general IQ (Mortensen et al, 1989).

\section{Current sample}

The Copenhagen Perinatal Cohort originally included 4668 males, but only 4280 survived the first 4 weeks of life. Individual identification numbers were introduced in 
Denmark in 1968 and it has been possible to obtain valid numbers for $\mathbf{4 1 1 6}$ males in the cohort (164 individuals were lost to study because of childhood mortality or emigration). Data from the Danish Psychiatric Register for these 4116 cohort members were obtained on 31 August 1999. However, BPP scores were only available for about $77 \%$ of the 4280 males who survived the first 4 weeks of life, and the current sample comprises 3289 men who appeared before the draft board at the mean age of 19.2 years (s.d.=1.3, range 16.4-26.2).

\section{Diagnostic classification}

Of the 3289 men included in our study, 350 $(10.6 \%)$ were identified in the Danish Psychiatric Central Register. In order to obtain diagnostic categories of reasonable size for analysis, ICD-8 and ICD-10 categories were combined to form the following nine diagnostic categories:

(a) schizophrenia and schizotypal personality disorders: 295.x diagnoses according to ICD-8 and F20.x or F21. $x$ diagnoses according to ICD-10;

(b) other psychotic disorders: 297.x and 298.x diagnoses and F20-F29 diagnoses (except F20.x and F21.x);

(c) mood disorders: 296.x diagnoses and F30-F39 diagnoses;

(d) neuroses and related disorders: $300 . x$ diagnoses and F40.x-F42.x and F44. $x$-F49. $x$;

(e) adjustment disorders: 307.x diagnoses and F43. $x$ diagnoses;

(f) personality disorders: 301.x diagnoses and F60.x-F61.x or F69.x diagnoses;

(g) alcohol-related disorders: 303.x diagnoses and F10.x diagnoses;

(h) other substance use disorders: 304.x diagnoses and F11.x-F19. $x$ diagnoses;

(i) other diagnoses: diagnoses not belonging in any of the above eight categories. The majority of the patients in this category had diagnoses that might also reflect adjustment disorder (for example, 39 patients had ICD-8 code 793 diagnosis).

\section{Data analysis}

The unregistered control sample comprised 2939 individuals. The observed control sample BPP mean score was 40.4, which is close to the 40.9 mean predicted from a regression formula describing secular trends in BPP scores (Teasdale \& Owen, 1989), and the standard deviation was 11.3, which is also close to the 11.4 observed for individuals born in 1954 1958 (the average year of birth of the control sample was 1960.8). In addition, the distribution of test scores was close to the normal distribution, and we decided to linearly transform BPP scores to a standardised scale with a mean of 100 and a standard deviation of 15 in the control sample, corresponding to the most frequently used IQ scales (Wechsler, 1958).

Using $t$-tests for independent samples, the mean transformed BPP score of each diagnostic category was compared with the mean of all unregistered control individuals. Analysis of covariance (ANCOVA) was conducted to adjust the BPP scores for parental social status and parental registration in the Psychiatric Register. Many patients were registered in several of the main diagnostic categories, and therefore $t$-tests and ANCOVA analyses of the diagnostic categories are based on partly overlapping patient samples. Consequently, we also conducted a multiple regression analysis with BPP score as the dependent variable and the nine diagnostic categories as independent variables.

In addition, the approximate length of time between appearing before the draft board and the date of first admission was calculated for each individual (the exact date of appearing before the draft board was not available, but the difference between the estimated and the exact date did not exceed 3 months). According to this interval, the individuals in each diagnostic category were classified into three subgroups: individuals who had already been admitted to an in-patient facility when they appeared before the draft board or who were admitted within the subsequent year; individuals who were admitted 1-5 years after the draft board examination; and individuals who were admitted more than 5 years after appearing before the draft board. Using ANOVA, the mean BPP scores in the three subgroups were compared. In addition to overall $F$-tests, contrasts were computed to evaluate differences between the three subgroup means (Rosenthal et al, 2000). Finally, those in the first of the three subgroups were excluded from the sample, and the multiple regression analysis with BPP score as the dependent variable and the nine diagnostic categories as independent variables was repeated on this reduced sample.

\section{RESULTS}

\section{Age at hospital admission and diagnosis}

Table 1 shows the numbers in each diagnostic category. Relatively few individuals had been given a diagnosis of mood disorder or a diagnosis of neuroses and related disorders. On the other hand, diagnoses such as adjustment disorders, personality disorders and alcohol-related disorders were common in this all-male sample. It is important to emphasise that the figures reflect hospital admissions only and do not necessarily indicate the 'true' cumulative incidence of the disorders in the sample. Furthermore, although the relatively few cases of hospital admission with a diagnosis of mood disorder might to some extent be the result of diagnostic conservatism, it is more likely to be a consequence of the fact that this is an all-male sample.

Diagnoses of schizophrenia, personality disorder and substance use disorders seem to be associated with first hospital admission at a relatively early age. Mood disorders, adjustment disorders and alcoholrelated disorders, on the other hand, are associated with older age at first admission. A corresponding pattern was observed for the mean intervals between appearing before the draft board and the time of first admission. The mean age at first admission was particularly low for the other diagnoses category, and it is remarkable that this category almost exclusively consisted of patients who had only been admitted once.

\section{Number of admissions and co-diagnoses}

Diagnoses of schizophrenia and of substance use disorder were both associated with relatively many admissions. Adjustment disorder, on the other hand, was associated with relatively few admissions (Table 1). For most diagnostic categories the average cohort member was registered in one additional category, but the average individual with the diagnosis of schizophrenia, other psychotic disorder or substance use disorder was registered in two additional categories. Table 2 shows the two most frequently diagnosed comorbid conditions. Chi-squared tests showed that diagnoses of schizophrenia and other psychotic disorder were positively associated $(P<0.0001)$ and that both these diagnoses were positively associated with substance use disorder $\quad(P<0.0001$ and $P<0.001$ 
Table I Psychiatric hospitalisation characteristics of members of the Copenhagen Perinatal Cohort (values are means)

\begin{tabular}{|c|c|c|c|c|c|c|c|}
\hline Diagnostic category & $n$ & $\begin{array}{l}\text { Age when first } \\
\text { admitted (years) }\end{array}$ & $\begin{array}{c}\text { Interval to first } \\
\text { admission (years) }\end{array}$ & $\begin{array}{c}\text { Age when first in a } \\
\text { diagnostic category } \\
\text { (years) }\end{array}$ & $\begin{array}{c}\text { Interval to first } \\
\text { time in a diagnostic } \\
\text { category (years) }\end{array}$ & $\begin{array}{c}\text { Total number } \\
\text { of admissions } \\
n\end{array}$ & $\begin{array}{c}\text { Total number } \\
\text { of diagnoses } \\
n\end{array}$ \\
\hline All in register & 350 & 26.0 & 7.0 & & & 4.4 & 1.3 \\
\hline $\begin{array}{l}\text { Schizophrenia and } \\
\text { schizotypal disorders }\end{array}$ & 50 & 24.7 & 5.8 & 28.9 & 10.0 & 15.4 & 2.7 \\
\hline Other psychotic disorders & 42 & 25.4 & 6.4 & 27.7 & 8.7 & 9.9 & 2.7 \\
\hline Mood disorders & 15 & 28.5 & 9.8 & 31.4 & 12.7 & 8.1 & 2.1 \\
\hline $\begin{array}{l}\text { Neuroses and related } \\
\text { disorders }\end{array}$ & 21 & 26.6 & 7.7 & 29.2 & 10.4 & 9.1 & 2.2 \\
\hline Adjustment disorders & 72 & 27.8 & 8.9 & 29.1 & 10.2 & 4.5 & 2.0 \\
\hline Personality disorders & 105 & 23.4 & 4.7 & 24.5 & 5.6 & 7.4 & 2.0 \\
\hline Alcohol-related disorders & 103 & 27.4 & 8.5 & 28.9 & 10.0 & 6.9 & 2.2 \\
\hline $\begin{array}{l}\text { Other substance use } \\
\text { disorders }\end{array}$ & 54 & 24.4 & 5.5 & 27.8 & 8.9 & 12.0 & 2.8 \\
\hline Other diagnoses & 71 & 21.7 & 2.7 & & & $1.0^{\prime}$ & \\
\hline
\end{tabular}

I. Two patients only had been admitted twice.

respectively). Adjustment disorder was negatively associated with schizophrenia $(P<0.05)$ and with personality disorder $(P<0.03)$, whereas personality disorder and substance use disorder showed a positive association $(P<0.02)$.

\section{Comparison with controls}

Table 3 shows the BPP mean scores for the control group and the nine diagnostic categories. Registration in the Psychiatric Register was associated with significantly lower BPP scores for all diagnostic categories except mood disorders and neuroses and related disorders. The differences between the control group mean and the means of most diagnostic categories were substantial, when compared with the size of the control group standard deviation. Among the six diagnostic categories significantly associated with low BPP score, the highest mean was for the category other psychotic disorder and the lowest mean was for the substance use disorder category. Table 3 shows that the mean of the category other psychotic disorder corresponds to a BPP mean of 92.4 and that the mean of the substance use category corresponds to a BPP mean of 86.5. Thus, in terms of standard deviation units, the mean of the former category was 0.5 s.d. below the mean of the controls, whereas the mean of the latter category was 0.9 s.d. below the control mean (7.6/15 and 13.5/15 respectively).

\section{Parental social status and psychiatric history}

Table 3 also shows that the pattern of mean parental social status scores corresponds to the pattern of BPP scores. Thus, registration in the Psychiatric Register was associated with significantly lower parental social status, except for mood disorders and for neuroses and related disorders. Table 4 shows that adjusting BPP scores for parental social status or for both parental social status and parental registration in the Psychiatric Register did not change the levels of significance substantially. It is noteworthy, however, that the adjusted regression coefficients for the categories of schizophrenia and schizotypal disorders and of other psychotic disorders indicated significantly lower BPP scores than for the control group only at the $5 \%$ level of significance.

\section{Comorbidity}

Table 5 shows the results of analysing the data of all cohort members in the study together and using indicator variables to code registration in diagnostic categories. Four

Table 2 Most frequent and next most frequent comorbid conditions diagnosed in the sample

\begin{tabular}{|c|c|c|}
\hline Diagnostic category & Most frequent co-diagnosis (\%) & Next most frequent co-diagnosis (\%) \\
\hline $\begin{array}{l}\text { Schizophrenia and } \\
\text { schizotypal disorders }\end{array}$ & Other psychotic disorder (46) & Substance use disorder (38) \\
\hline Other psychotic disorders & Schizophrenia (55) & Substance use disorder (33) \\
\hline Mood disorders & Other psychotic disorder (20) & $\begin{array}{l}\text { Adjustment disorder (20) } \\
\text { Alcohol-related disorder (20) }\end{array}$ \\
\hline $\begin{array}{l}\text { Neuroses and related } \\
\text { disorders }\end{array}$ & Alcohol-related disorder (38) & Personality disorder (24) \\
\hline Adjustment disorders & Alcohol-related disorder (26) & $\begin{array}{l}\text { Personality disorder (19) } \\
\text { Substance use disorder (19) }\end{array}$ \\
\hline Personality disorders & Alcohol-related disorder (33) & Substance use disorder (23) \\
\hline Alcohol-related disorders & Personality disorder (33) & Substance use disorder (19) \\
\hline Substance use disorders & Personality disorder (44) & Alcohol-related disorder (37) \\
\hline Other diagnoses & Not applicable & \\
\hline
\end{tabular}


Table 3 Scores on the Børge Priens Prøve (BPP) IQ test and parental social status in the control sample and in diagnostic categories

\begin{tabular}{|c|c|c|c|c|c|c|}
\hline \multirow[t]{2}{*}{ Diagnostic category } & \multicolumn{3}{|c|}{ BPP score } & \multicolumn{3}{|c|}{ Parental social status } \\
\hline & Mean $(95 \% \mathrm{Cl})$ & s.d. & $P^{\prime}$ & Mean $(95 \% \mathrm{Cl})$ & s.d. & $P^{\prime}$ \\
\hline Control group & $100.0(99.5-100.5)$ & 15.0 & & $4.1(4.0-4.2)$ & 1.9 & \\
\hline All in register & $90.8(89.2-92.4)$ & 15.0 & 0.0001 & $3.2(3.0-3.4)$ & $\mathrm{I} .5$ & $<0.0001$ \\
\hline Schizophrenia and schizotypal disorders & $92.2(87.7-96.7)$ & 16.2 & 0.0003 & $3.1(2.7-3.5)$ & 1.4 & 0.0005 \\
\hline Other psychotic disorders & $92.4(87.7-97.1)$ & 15.6 & 0.0011 & $3.3(2.8-3.8)$ & 1.5 & 0.0109 \\
\hline Mood disorders & 97.1 (88.1-106.I) & 17.7 & 0.46 & $3.7(2.8-4.6)$ & 1.7 & 0.40 \\
\hline Neuroses and related disorders & $96.6(91.8-101.4)$ & 11.2 & 0.30 & $3.8(3.0-4.6)$ & 1.5 & 0.49 \\
\hline Adjustment disorders & 89.5 (86.1-92.9) & 14.7 & $<0.0001$ & $3.2(2.9-3.5)$ & $\mathrm{I} .4$ & 0.0001 \\
\hline Personality disorders & $90.2(87.3-93.1)$ & 15.4 & $<0.0001$ & $3.1(2.8-3.4)$ & 1.6 & $<0.0001$ \\
\hline Alcohol-related disorders & $87.4(84.4-90.4)$ & 15.4 & $<0.0001$ & $3.2(2.9-3.5)$ & $\mathrm{I} .4$ & $<0.0001$ \\
\hline Substance use disorders & $86.5(82.6-90.4)$ & 14.7 & $<0.0001$ & $3.1(2.7-3.5)$ & 1.4 & 0.0002 \\
\hline Other diagnoses & 89.7 (86.3-93.1) & 14.5 & $<0.0001$ & $3.2(2.8-3.6)$ & 1.6 & 0.0006 \\
\hline
\end{tabular}

I. Probability values refer to the significance of the difference between each diagnostic category and the unregistered control sample ( $t$-tests).

Table 4 Regression coefficients coding the difference between each diagnostic category and the control sample, adjusted for parental social status and for parental registration in the Danish Psychiatric Register

\begin{tabular}{|c|c|c|c|c|}
\hline \multirow[t]{2}{*}{ Diagnostic category } & \multicolumn{2}{|c|}{ Adjustment for parental social status } & \multicolumn{2}{|c|}{ Adjustment for parental social status and registration } \\
\hline & Coefficient $(95 \% \mathrm{Cl})$ & $P^{\prime}$ & Coefficient $(95 \% \mathrm{Cl})$ & $P^{\prime}$ \\
\hline All in register & $-6.8(-8.3$ to -5.2$)$ & $<0.0001$ & $-6.5(-8.1$ to -4.9$)$ & $<0.000 \mathrm{I}$ \\
\hline Schizophrenia and schizotypal disorders & $-5.0(-8.8$ to $-I . I)$ & 0.0122 & $-4.5(-8.4$ to -0.6$)$ & 0.0234 \\
\hline Other psychotic disorders & $-5.4(-9.6$ to $-I . I)$ & 0.0130 & $-5.0(-9.2$ to -0.8$)$ & 0.0203 \\
\hline Mood disorders & $-1.6(-8.7$ to 5.4$)$ & 0.65 & $-I . I(-8 . I$ to 5.9$)$ & 0.76 \\
\hline Neuroses and related disorders & $-2.5(-8.4$ to 3.4$)$ & 0.41 & $-2.3(-8.2$ to 3.6$)$ & 0.44 \\
\hline Adjustment disorders & $-7.7(-10.9$ to -4.4$)$ & $<0.0001$ & $-7.4(-10.6$ to -4.1$)$ & $<0.0001$ \\
\hline Personality disorders & $-7.1(-9.8$ to -4.3$)$ & $<0.0001$ & $-6.7(-9.4$ to -4.0$)$ & $<0.0001$ \\
\hline Alcohol-related disorders & $-10.1(-12.8$ to -7.4$)$ & $<0.0001$ & $-9.9(-12.6$ to -7.1$)$ & $<0.0001$ \\
\hline Substance use disorders & $-10.5(-14.3$ to -6.8$)$ & $<0.0001$ & $-10.1(-13.8$ to -6.3$)$ & $<0.0001$ \\
\hline Other diagnoses & -7.8 ( -11.0 to -4.5$)$ & $<0.0001$ & $-7.5(-10.8$ to -4.3$)$ & $<0.0001$ \\
\hline
\end{tabular}

I. Probability values refer to the significance of the adjusted difference between each diagnostic category and the unregistered control sample (analysis of covariance).

diagnostic categories were not significantly associated with low BPP scores: schizophrenia and schizotypal disorders, other psychotic disorders, mood disorders, and neuroses and related disorders. The association with low BPP scores remained significant for five other diagnostic categories: adjustment disorders, personality disorders, alcohol-related disorders, substance use disorders and other diagnoses). Table 2 shows substantial overlap between the schizophrenia and other psychotic disorders categories, but none of these diagnoses showed significant associations with BPP scores when the other category was excluded from the regression model ( $P=0.89$ and $P=0.64$, respectively). The categories alcohol-related disorders and (in particular) substance use disorders were frequent co-diagnoses of schizophrenia and other psychotic disorders. Since Tables 3 and 4 show that alcohol and substance use disorders were associated with very low BPP scores, we conducted a regression analysis without indicator variables for these diagnoses. This analysis also showed no significant association between BPP scores and schizophrenia or other psychotic disorders $(P=0.26$ and $P=0.36$, respectively).

\section{Interval between testing and first admission}

Table 6 shows the results of classifying all 350 individuals recorded in the Psychiatric Register into three subgroups according to the interval between appearing before the draft board and the time of first admission. One-way ANOVA showed significant overall F-test only for the categories of schizophrenia and schizotypal disorders, adjustment disorders and substance use disorders. For these categories, contrasts showed that the mean of the $>5$ year subgroup was significantly higher than the 
Table 5 Regression coefficients coding the difference between each diagnostic category and the control sample adjusted for registration in other diagnostic categories

\begin{tabular}{lcr}
\hline Diagnostic category & Coefficient $(95 \% \mathrm{Cl})$ & $P^{\prime}$ \\
\hline Schizophrenia and schizotypal disorders & $0.2(-4.9$ to 5.3$)$ & 0.94 \\
Other psychotic disorders & $-1.2(-6.6$ to 4.1$)$ & 0.65 \\
Mood disorders & $2.1(-5.6$ to 9.8$)$ & 0.59 \\
Neuroses and related disorders & $3.3(-3.3$ to 9.8$)$ & 0.33 \\
Adjustment disorders & $-6.0(-9.7$ to -2.3$)$ & 0.0013 \\
Personality disorders & $-4.6(-7.8$ to -1.4$)$ & 0.0048 \\
Alcohol-related disorders & $-8.8(-12.0$ to -5.6$)$ & $<0.000 \mathrm{I}$ \\
Substance use disorders & $-6.5(-1 \mathrm{II}$ to -2.0$)$ & 0.0052 \\
Other diagnoses & $-10.2(-13.7$ to -6.7$)$ & $<0.000 \mathrm{I}$ \\
\hline
\end{tabular}

I. Probability values refer to the significance of the adjusted differences.

means of the subgroups with intervals of $<1$ year and $1-5$ years. The table shows similar trends for the categories of other psychotic disorders and personality disorders, whereas the inconsistent results for mood disorders and neuroses and related disorders most probably reflect small subgroup sample sizes and low power.

Differences between the $<1$ year and the 1-5 year subgroups were insignificant and for most categories small. The results of excluding the 75 men in the $<1$ year subgroup and adjusting for comorbid diagnoses are presented in Table 7 . The adjusted regression coefficients in this table do not deviate substantially from the coefficients in Table 5 , and the higher $P$-values in
Table 7 seem to reflect loss of power due to smaller group sizes.

\section{DISCUSSION}

Seven diagnostic categories were associated with low premorbid BPP test scores, but this was not the case for the categories of mood disorders and neuroses and related disorders. The seven categories showed substantial cognitive deficits, ranging from 7.6 to 13.5 on a traditional IQ scale and corresponding to $0.5-0.9$ of the BPP standard deviation of the unregistered control sample. The same seven diagnostic categories were also associated with relatively low parental social status, but neither parental social status nor parental psychiatric hospitalisation explains the relatively low BPP scores.

When comorbid diagnoses were included as covariates, the adjusted regression coefficients for five categories (adjustment disorders, personality disorders, alcoholrelated disorders, substance use disorders and other diagnoses) indicated significantly lower mean BPP scores than the mean of the unregistered controls, whereas this was not the case for schizophrenia and schizotypal disorders and other psychotic disorders. Except for mood disorders, neuroses and related disorders and other diagnoses, BPP scores were higher - although not necessarily significantly so - for individuals first admitted more than 5 years after BPP testing. Differences in BPP scores between those admitted within 1 year and those admitted 1-5 years after testing were small and inconsistent, and an analysis excluding those admitted within 1 year essentially confirmed the results for the full sample.

It should be kept in mind that these observations refer to associations between the possibly unreliable hospital diagnoses in the Danish Psychiatric Register and BPP performance. However, noise introduced by unreliable diagnoses may weaken rather than strengthen associations between diagnostic categories and BPP scores. In addition, although unreliable diagnoses and misclassification of patients might affect results

Table 6 Scores on the Børge Priens Prøve (BPP) IQ test for subgroups classified according to the interval between testing and first admission

\begin{tabular}{|c|c|c|c|c|c|c|c|}
\hline \multirow[t]{2}{*}{ Diagnostic category } & \multicolumn{2}{|c|}{ Interval $<$ I year } & \multicolumn{2}{|c|}{ Interval I-5 years } & \multicolumn{2}{|c|}{ Interval $>5$ years } & \multirow[t]{2}{*}{$P^{\prime}$} \\
\hline & $n$ & Mean $(95 \% \mathrm{Cl})$ & $n$ & Mean $(95 \% \mathrm{Cl})$ & $n$ & Mean $(95 \% \mathrm{Cl})$ & \\
\hline All registered patients & 75 & $88.2(84.9-91.5)$ & 88 & $90.3(87.2-93.4)$ & 187 & 92.1 (89.9-94.3) & 0.15 \\
\hline $\begin{array}{l}\text { Schizophrenia and } \\
\text { schizotypal disorders }\end{array}$ & II & $85.9(75.4-96.4)$ & 15 & $87.6(79.8-95.4)$ & 24 & $98.0^{2}(92.2-103.8)$ & 0.0478 \\
\hline Other psychotic disorders & II & 88.9 (77.9-99.9) & 9 & 88.1 (75.4-100.8) & 22 & $95.8(90.8-100.8)$ & 0.33 \\
\hline Mood disorders & 2 & $90.2(72.0-108.4)$ & 4 & III.8 (I05.5-II8.I) & 9 & 92.1 (79.6-104.6) & 0.15 \\
\hline $\begin{array}{l}\text { Neuroses and related } \\
\text { disorders }\end{array}$ & 4 & $93.2(82.6-103.8)$ & 5 & $101.6(94.2-109.0)$ & 12 & $95.6(88.6-102.6)$ & 0.50 \\
\hline Adjustment disorders & 12 & 82.4 (74.7-90.I) & 12 & 84.1 (77.9-90.3) & 48 & $92.6^{2}(88.4-96.8)$ & 0.0340 \\
\hline Personality disorders & 36 & $88.1(83.0-93.2)$ & 25 & $87.8(82.1-93.5)$ & 44 & 93.3 (88.7-97.9) & 0.22 \\
\hline Alcohol-related disorders & 14 & $84.4(76.8-92.0)$ & 22 & 86.1 (79.5-92.7) & 67 & 88.4 (84.7-92.I) & 0.62 \\
\hline Substance use disorders & 12 & $81.2(73.1-89.3)$ & 15 & $80.2(73.9-86.5)$ & 27 & $92.4^{2}(87.1-97.7)$ & 0.0109 \\
\hline Other diagnoses & 12 & 86.4 (8I.I-9I.7) & 15 & 91.4 (86.9-95.9) & 27 & 91.2 (81.5-100.9) & 0.40 \\
\hline
\end{tabular}

I. Probability values refer to the overall $F$-value for one-factor analysis of variance of the differences among the three subgroups.

2. Significant difference between the mean of the $>5$ year subgroup and the means of the two other subgroups. 
Table 7 Reduced sample: regression coefficients coding the difference between each diagnostic category and the control sample adjusted for registration in other diagnostic categories

\begin{tabular}{lcc}
\hline Diagnostic category & Coefficient $(95 \% \mathrm{Cl})$ & $P^{1}$ \\
\hline Schizophrenia and schizotypal disorders & $0.9(-4.7$ to 6.5$)$ & 0.74 \\
Other psychotic disorders & $-1.7(-7.8$ to 4.4$)$ & 0.58 \\
Mood disorders & $1.1(-7.1$ to 9.4$)$ & 0.79 \\
Neuroses and related disorders & $2.0(-5.2$ to 9.2$)$ & 0.59 \\
Adjustment disorders & $-5.1(-9.1$ to -1.1$)$ & 0.0129 \\
Personality disorders & $-3.4(-7.3$ to 0.5$)$ & 0.08 \\
Alcohol-related disorders & $-9.3(-12.7$ to -5.9$)$ & $<0.0001$ \\
Substance use disorders & $-6.4(-11.5$ to -1.4$)$ & 0.0123 \\
Other diagnoses & $-8.6(-12.9$ to -4.2$)$ & 0.0001 \\
\hline
\end{tabular}

I. Probability values refer to the significance of the adjusted differences.

for individual diagnostic categories (e.g. personality disorders), it is unlikely that such factors explain the overall picture of associations between several broad diagnostic categories and BPP score. Strong evidence that low IQ test scores are not only associated with psychiatric hospitalisation and hospital diagnoses is provided by a recent cross-sectional study of associations between cognitive test scores and psychopathological screening diagnoses in male adolescents appearing before the Israeli draft board. In that study, mean cognitive test scores were significantly poorer for almost all diagnostic groups than for controls, and observed effect sizes were in the range 0.3-1.6 (Weiser et al, 2004).

\section{Explaining the association}

Several mechanisms may explain the association between IQ and mental disease. An aetiological hypothesis assumes that low IQ has a direct or indirect role in the aetiology of a mental disease; thus, it is possible that low IQ plays a part in the development of risk drinking (Windle $\&$ Blane, 1989; Mortensen et al, 2005) or antisocial personality traits (Loney et al, 1983; Kandel et al, 1988). For schizophrenia, it might be assumed that low IQ mediates the effects of adverse prenatal factors and birth complications, although there is evidence that IQ may be an independent risk factor (Gunnell et al, 2002). Second, common genetic and environmental factors may affect both the development of mental disease and cognitive development: for example, obstetrical complications might affect both the risk of schizophrenia and cognitive development (Boog, 2004). Thus, we observed that parental social status was associated with both offspring IQ and mental disease - but we also observed that neither parental social status nor genetic (family) disposition to mental disease could explain the link between IQ and disease (parental psychiatric admission is obviously a general and nonspecific indicator of genetic disposition).

A third possibility is that mental disease affects IQ test scores, which might occur in several ways. A developmental hypothesis assumes that personality traits associated with the risk of developing a mental disease adversely affect cognitive development. Thus, deviant personality traits in people who go on to develop schizophrenia may be associated with less optimal cognitive development (Malmberg et al, 1998). A test performance hypothesis assumes that premorbid traits or early symptoms affect motivation and test performance when young men appear before the draft board. Thus, some personality disorders might be associated with low motivation, and taking the BPP under the influence of alcohol or other substances might lead to low test scores - although in our sample this seems an unlikely explanation of the association between BPP scores and alcoholrelated and other substance use disorders, because a medical examination is part of appearing before the draft board, and because of the average 10-year and 8.9-year intervals between taking the BPP and the first admissions with these diagnoses (see Table 1). Finally, there is a 'dementia' hypothesis, according to which cognitive impairment may be the direct result of mental diseases such as alcoholism or schizophrenia. Because of the young age of the individuals in our study, it is doubtful that such a mechanism explains the association between alcoholism and low BPP scores, but it could have a role in very early cases of schizophrenia.

A fourth possibility is that IQ is primarily associated with the risk of hospitalisation, or the likelihood of obtaining a certain diagnosis when hospitalised. Thus, one study has reported that IQ is an independent predictor of lifetime psychiatric contact (Walker et al, 2002), and it is likely that IQ is a strong determinant of the ability to cope with crises and life events and that this ability affects the risk of admission to a psychiatric department. This may partly explain the association between adjustment disorders and low IQ and the similar results for the other diagnoses category (typically admitted only once to psychiatric treatment). A link between IQ and risk of admission may also have a role in personality disorders, but it is also possible that low IQ affects the risk of receiving a diagnosis of personality disorder or alcoholism relatively early (i.e. patients with a higher IQ may be able to hide their antisocial behaviour or alcohol problems). However, a recent follow-up study of a non-hospitalised subsample from the Copenhagen Perinatal Cohort showed an association between low IQ and self-reported risk drinking, suggesting that the association between low IQ and alcohol-related disorder does not only reflect a link between IQ and risk of hospitalisation with an alcohol diagnosis (Mortensen et al, 2005).

Our results indicate significant premorbid cognitive deficits in several psychiatric diagnostic categories, and it is likely that many - if not all - of the mechanisms described above contribute to the low premorbid IQ observed for most diagnostic categories. Several of these mechanisms (the aetiological hypothesis, common genetic and environmental factors and the developmental hypothesis) may explain low IQ in neurodevelopmental disorders (Bradshaw, 2001). However, low BPP scores were observed for both psychotic disorders (schizophrenia, and the category of other psychotic disorders, which included paranoid psychosis) and for nonpsychotic disorders (adjustment disorders, personality disorders, alcohol-related disorders and other substance use disorders). In interpreting the lack of evidence for low premorbid IQ in mood disorder (affective illness) and neuroses and related disorders, 
the small number of individuals in these categories should be borne in mind. Thus, although we were able to confirm low IQ in those later developing schizophrenia, our results suggest that low premorbid IQ is not specific for schizophrenia and related disorders, and may indeed show a stronger association with adjustment disorders, personality disorders, and alcohol-related and substance use disorders. The cohort members were $38-40$ years old when the follow-up was completed, thus ensuring that the vast majority of incident cases with schizophrenia would have been identified. The in-patient register diagnoses of schizophrenia can be considered to be reliable in Denmark (Munk-Jørgensen, 1995).

\section{Interval between testing and first admission}

In this register-based study the first admission to a psychiatric department was the earliest available indicator of mental disorder. In general, the longer the interval between IQ testing and first admission, the greater the likelihood that a low IQ score is not an effect of mental disorder. Table 1 shows that for all diagnostic categories the average individual was admitted several years after appearing before the draft board, and Table 6 shows that the majority of patients were admitted more than 5 years after BPP testing. For most diagnostic categories these patients obtained higher BPP mean scores than those admitted sooner, but perhaps it is more remarkable that differences between those admitted within 1 year and those admitted 1-5 years after testing were small and inconsistent. This pattern suggests that previous and existing mental disorders do not have substantial negative effects on BPP scores. For schizophrenia and related disorders, the low BPP mean for those admitted within 5 years of testing may reflect the effects of prodromal symptoms on test performance (Rabinowitz et al, 2000), but perhaps more probably a complex development with premorbid traits leading to low cognitive ability, which in turn leads to vulnerability and early psychosis. For schizophrenia as well as adjustment disorders and substance use disorders, the differences between those admitted within 5 years and those admitted later may also reflect links between cognitive ability, coping strategies and risk of hospitalisation. In this perspective it is, however, remarkable that the difference between early and late admission is relatively small for alcohol-related disorders, suggesting that the association between low IQ and alcohol-related disorders is not entirely explained by a link between low IQ and the likelihood of hospitalisation and early alcohol diagnosis.

\section{Comorbidity}

Attempts to interpret our results should take into account the facts that individual diagnoses often change over the life span (e.g. from personality disorder to schizophrenia) and that admission to a psychiatric department often results in several discharge diagnoses. Thus, there is evidence from the Swedish conscript study (Lewis et al, 2000) that nearly $40 \%$ of men who developed schizophrenia would have received a psychiatric diagnosis of a nonpsychotic disorder at the age of 18 years. In our study sample, $46 \%$ of the men with schizophrenia were also registered in the category of other psychotic disorders, and $38 \%$ were registered in the category of other substance use disorders. On the other hand, alcohol-related disorders and personality disorders tended to cluster together (about 33\% diagnostic overlap). When we adjusted for all diagnostic categories (Tables 5 and 7), the regression coefficients indicated particularly low BPP scores for alcohol-related disorders and other diagnoses (followed by substance use and adjustment disorders). We believe that adjusting for co-diagnoses is more realistic than constructing a diagnostic hierarchy and assigning each patient to only one diagnostic category (this procedure has to be based on strong assumptions about relationships among mental disorders, and for individual patients these assumptions cannot be verified in a register-based study). However, the results of adjusting for co-diagnoses may be ambiguous, since some diagnostic categories may typically be associated with more co-diagnoses than other categories and there must be much overlapping variance between some of the categories. Our analyses suggested that collinearity with alcohol and substance use disorders or other psychotic disorders did not explain the results for schizophrenia. When interpreting the lack of significance for schizophrenia in Tables 5 and 7 , it should also be borne in mind that the unadjusted mean in Table 3 confirms other studies that have not adjusted for co-diagnoses and observed an association between low IQ scores and schizophrenia. The unadjusted mean describes the observed IQ of patients with a diagnosis of schizophrenia, whereas the adjusted regression coefficients reflect both the pattern of associations among the diagnostic categories and between each diagnostic category and IQ.

\section{Implications of our findings}

We have demonstrated that most broad diagnostic categories of mental disorder are associated with relatively low premorbid IQ. Both low IQ and mental disorder may be considered to be indicators of suboptimal brain development, but many mechanisms may contribute to explain the association between IQ and mental disorder. The range of mental disorders and the observed effect sizes should be considered. If our results can be generalised, it is unlikely that any personality trait or other psychological characteristic - perhaps except the broad personality dimension of 'neuroticism' - has a stronger association with mental disorder than IQ. This has important implications for both research and clinical practice. Scores on IQ tests correlate with many neuropsychological tests of specific cognitive functions and with many other psychological and social variables (Gottfredson, 2002). Consequently, the association with IQ should be considered in any theoretical account of the development of the relevant disorders, and - if possible-premorbid IQ should be controlled for in studies comparing patient samples (e.g. people with schizophrenia or alcoholism) and normal controls. In clinical practice, the relatively high frequency of low premorbid IQ in many diagnostic categories should also be taken into account when choosing appropriate therapy and when interpreting the cognitive performance of individual patients (e.g. neuropsychological test scores in cases of long-term alcoholism). It should, however, not be forgotten that patients show large individual differences in IQ scores and that a substantial number of patients in all diagnostic categories are of normal or abovenormal IQ (in our study sample about $28 \%$ of the 350 patients obtained BPP scores corresponding to an IQ of 100 or higher). Finally, our study describes associations between diagnostic categories and scores on a Danish IQ test, and to evaluate whether our findings can be generalised, 
similar studies in other countries and cultures are needed.

\section{ACKNOWLEDGEMENTS}

This study has been supported by United States Public Health Service (USPHS) grants HDI7655 and HD20263 from the National Institute of Child Health and Human Development to J.M.R.; USPHS grant DA05056 from the National Institute on Drug Abuse to J.M.R.; Sygekassernes Helsefond (Health Insurance Foundation) grant to H.J.S.; grant 9700093 from the Danish Research Councils as well as grant 1400/2-4-1997 from the Danish National Board of Health to E.L.M.

Thanks are due to Vibeke Munk, MA, for help with the manuscript and critical comments.

\section{REFERENCES}

Boog, G. (2004) Obstetrical complications and subsequent schizophrenia in adolescent and young adult offsprings: is there a relationship? European Journal of Obstetrics and Gynecology and Reproductive Biology, II4, 130-136.

Bradshaw, J. L. (200I) Developmental Disorders of the Frontostriatal System. Hove: Psychology Press.

Cannon, M., Walsh, E., Hollis, C., et al (200I) Predictors of later schizophrenia and affective psychosis among attendees at a child psychiatry department. British Journal of Psychiatry, 178, 420-426.

Caspi, A., Moffit, T. E., Newman, D. L., et al (1996) Behavioural observations at age 3 years predict adult psychiatric disorders. Archives of General Psychiatry, 53, 1033-1039.

David, A. S., Malmberg, A., Brandt, L., et al (1997) $\mathrm{IQ}$ and risk for schizophrenia: a population-based cohort study. Psychological Medicine, 27, I3II-1323.

Davidson, M., Reichenberg, A., Rabinowitz, J., et al (1999) Behavioral and intellectual markers for schizophrenia in apparently healthy male adolescents. American Journal of Psychiatry, 156, 1328-1335.

Gottfredson, L. S. (2002) g: Highly general and highly practical. In The General Factor of Intelligence - How General Is It? (eds R. J. Sternberg \& E. L. Grigorenko), pp. 33I-380. London: Lawrence Erlbaum.

Gunnell, D., Harrison, G., Rasmussen, F., et al (2002) Associations between premorbid intellectual performance, early life exposures and early-onset schizophrenia: cohort study. British Journal of Psychiatry, I8I, 298-305.

Jones, P., Rodgers, B., Murray, R., et al (1994) Child developmental risk factors for adult schizophrenia in the British 1946 birth cohort. Lancet, 344, 1398-1402.

Kandel, E., Mednick, S. A., Kirkegaard-Sorensen, L., et al (1988) IQ as a protective factor for subjects at high risk for antisocial behavior. Journal of Consulting and Clinical Psychology, 56, 224-226.

Lewis, G., David, A. S., Malmberg, A., et al (2000) Non-psychotic psychiatric disorder and subsequent risk of schizophrenia: cohort study. British Journal of Psychiatry, 177, 416-420.

Loney, J., Whaley-Klahn, M. A., Kosier, T., et al (1983) Hyperactive boys and their brothers at 21: predictors of aggressive and antisocial outcomes. In Prospective Studies

\section{CLINICAL IMPLICATIONS}

- The mean performance of psychiatric patients on IQ tests is relatively low and evaluation of cognitive function should be an integrated aspect of thorough clinical assessment.

- Low premorbid IQ is associated not only with schizophrenia and related disorders, but also with several broad diagnostic categories, including alcohol and substance misuse.

- In individual patients poor cognitive function does not necessarily reflect effects of mental disorders (e.g. alcohol misuse), but may rather reflect low premorbid IQ.

\section{LIMITATIONS}

- The study was register-based; only patients admitted to hospital were included and the diagnostic categories were based on hospital diagnoses.

- The study investigated an all-male sample; it is not known to what extent the results may be generalised to female psychiatric patients.

- For diagnostic categories such as mood disorders and neuroses and related disorders, sample sizes were too small to permit definitive conclusions about the potential association with $\mathrm{IQ}$.

ERIK LYKKE MORTENSEN, CandPsych, Department of Health Psychology, Institute of Public Health, University of Copenhagen; HOLGER JELLING SØRENSEN, MD, PhD, Department of Psychiatry (Amager), Copenhagen University Hospital, Copenhagen; HANS HENRIK JENSEN, MagArt, Department of Health Psychology, Institute of Public Health, University of Copenhagen, Copenhagen, Denmark; JUNE MACHOVER REINISCH, PhD, Kinsey Institute for Research in Sex, Gender and Reproduction, Indiana University, Bloomington, Indiana; SARNOFFA. MEDNICK, DrMedSci, Social Science Research Institute and Department of Psychology, University of Southern California, Los Angeles, California, USA

Correspondence: Erik Lykke Mortensen, Department of Health Psychology, University of Copenhagen, Øster Farimagsgade 5A, PO Box 2099, I0I4 Copenhagen K, Denmark. Tel: +453532 7839; fax: +453532 7748; e-mail: e.I.mortensen@pubhealth.ku.dk

(First received 18 May 2004, final revision 9 November 2004, accepted 14 December 2004)

of Crime and Delinquency (eds K. T. Van Dusen \& S. A. Mednick). Boston, MA: Kluwer-Nijhoff.

Malmberg, A., Lewis, G., David, A., et al (1998) Premorbid adjustment and personality in people with schizophrenia. British Journal of Psychiatry, 172, 308-313.

Mortensen, E. L., Reinisch, J. M., Teasdale, T.W. (1989) Intelligence as measured by the WAIS and a military draft board group test. Scandinavian Journal of Psychology, 30, 315-318.

Mortensen, E. L., Jensen, H. H., Sanders, S. A., et a (2005) Associations between volume of alcohol consumption and social status, intelligence and personality in a sample of young adult Danes. Scandinavian Journal of Psychology, in press.

Munk-Jørgensen, P. (1995) Faldende

Førstegangsindlæggelsesrater for Skizofreni i Danmark 1970-1991. Århus: Århus University.
Munk-Jørgensen, P. \& Mortensen, P. B. (1997) The Danish Psychiatric Central Register. Danish Medical Bulletin, 44, 82-84.

Rabinowitz, J., Reichenberg, A., Weiser, M., et al (2000) Cognitive and behavioural functioning in men with schizophrenia both before and shortly after first admission to hospital: cross-sectional analysis. British journal of Psychiatry, 177, 26-32.

Reinisch, J. M., Mortensen, E. L. \& Sanders, S. A. (1993) The prenatal development project. Acto Psychiatrica Scandinavica, 370, 54-6I.

Rosenthal, R., Rosnov, R. L. \& Rubin, D. B. (2000) Contrast and Effect Sizes in Behavioural Research. Cambridge: Cambridge University Press.

Teasdale, T.W. \& Owen, D. R. (1989) Continuing secular increases in intelligence and a stable prevalence of high intelligence levels. Intelligence, 13, 255-262.

Walker, N. P., McConville, P. M., Hunter, D., et al (2002) Childhood mental ability and lifetime psychiatric 
contact. A 66 year follow-up study of the 1932 Scottish Mental Ability Survey. Intelligence, 30, 233-245.

Wechsler, D. (1958) The Measurement and Appraisal of Adult Intelligence. Baltimore, MD: Williams \& Wilkins.

Weiser, M., Reichenberg, A., Rabinowitz, J., et al (2004) Cognitive performance of male adolescents is lower than controls across psychiatric disorders: population-based study. Acta Psychiatrica Scandinavica, II0, 47I-475.
Windle, M. \& Blane, H.T. (1989) Cognitive ability and drinking behavior in a national sample of young adults. Alcoholism: Clinical and Experimental Research, 13, 43-48.

World Health Organization (1974) International Statistical Classification of Diseases and Related Health Problems (ICD-8). Geneva: WHO.

World Health Organization (1992) International Statistical Classification of Diseases and Related Health Problems (ICD-I0). Geneva: WHO
Zachau-Christiansen, B. \& Ross, E. M. (1975) Babies: Human Development During the First Year. New York: John Wiley.

Zammit, S., Allebeck, P., David, A. S., et al (2004) A longitudinal study of premorbid IQ score and risk of developing schizophrenia, bipolar disorder, severe depression, and other nonaffective psychoses. Archives of General Psychiatry, 61, 354-360. 